\title{
Autologous Stem Cell Transplantation in Patients with Acute Myeloid Leukemia: a Single-Centre Experience
}

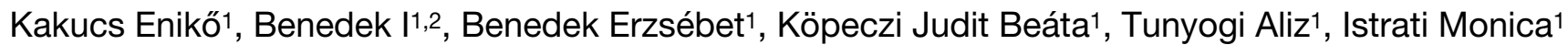 \\ ${ }^{1}$ Clinical Hematology and Bone Marrow Transplantation Clinic, Tîrgu Mureș, Romania \\ 2 University of Medicine and Pharmacy, Tîrgu Mureș, Romania
}

\begin{abstract}
Introduction: Autologous haemopoietic stem cell transplantation (SCT) is an important treatment modality for patients with acute myeloid leukemia with low and intermediate risk disease. It has served advantages over allogenic transplantation, because it does not need a matched donor, there is no graft versus host disease, there are less complications and a faster immune reconstitution than in the allo-setting. The disadvantage is the lack of the graft versus leukaemia effect.

Materials and methods: In the Bone Marrow Transplantation Unit Tîrgu Mureș 14 patients with acute myeloid leukemia received an autologous SCT. Mobilization of the stem cells was performed using chemotherapy and granulocytic colony stimulating factor. The conditioning regimen for SCT consists in monotherapy with busulfan (Bu) 16 mg/kg, BuCy: busulfan in combination with Cyclophosphamide (CY) $120 \mathrm{mg} /$ $\mathrm{kg}$ or BuMel: Busulfan in association with Melphalan (Mel) $140 \mathrm{mg} / \mathrm{m}^{2}$.

Results: The median patient age was 36 years (range 20-55), 9 (64\%) were males and 5 (36) were females and the median time interval from diagnosis to autologous SCT was 9 months (range 3-25). All the patients were transplanted successfully, all of them achieved a sustained neutrophil count (>0.5 G/L), median time 11 days (9-15) and platelet count (> 20 G/L) median time 14 days (10-19) after transplantation. Conclusions: We conclude that autologous stem cell transplantation is an effective treatment in acute myeloid leukemia with the possibility of long survival, particularly in patients with standard risk disease.
\end{abstract}

Keywords: acute myeloid leukemia, autologous stem cell transplantation

Received: 7 May 2012

\section{Introduction}

Autologous hematopoietic stem cell transplantation (SCT) is an important therapeutic option in patients with acute myeloid leukemia with no identical sibling for an allogeneic transplantation.

Young patients (age under 60 or 65 years) with goodrisk AML in first CR were recommended to undergo consolidation with high dose chemotherapy \pm autologous SCT. Patients with poor-risk AML were recommended to undergo allogeneic SCT [1].

Several randomized studies, comparing allogeneic transplants in patients with HLA matched siblings to autologous transplantation and to conventional chemotherapy, have shown the superiority of the allogeneic transplant approach to the other approaches, but also the superiority of autografting over conventional chemotherapy. None of the studies have shown the superiority of conventional chemotherapy $[2,3,4]$.

Autologous stem cell transplantation has several advantages and disadvantages in relation to allogeneic stem cell transplantation. The faster hematological engraftment, the possibility of applying this treatment to older patients, the lower incidence of complications, the faster immune re-

Correspondence to: Enikő Kakucs

E-mail: enikokakucs@yahoo.com constitution and the absence of graft-versus-host disease are positive factors [5]. Nevertheless, autologous stem cell transplantation is associated with several disadvantages: the lack of "graft versus leukaemia effect", inefficient number of peripheric stem cells at mobilization and a higher incidence of relapses [6,7].

In this study we report the results of 14 patients with acute myeloid leukemia, who underwent autologous peripheral stem cell transplantation.

\section{Material and methods}

We retrospectively analyzed 14 patients, transplanted at the Bone Marrow Transplantation Center in Tîrgu Mureș. The FAB classification of these acute myeloid leukemia patients was: LAM4 in 10 patients, LAM5 in 3 patients and 1 patient with LAM2. The median age at transplantation was 36 years (range 20-55), 9 patients $(64 \%)$ were males and $5(36 \%)$ were females. The median time interval from diagnosis to autologous SCT was 9 months (range 3-25).

The distribution of cytogenetic categories was defined as low risk in 10 patients and intermediate risk in 4 patients.

Autologous stem cell transplantation has been used as the consolidation treatment in 12 patients in first CR1 and in two patients in second CR2. Complete remission was defined as normal bone marrow morphology with 
Table I. Characteristics of patients

\begin{tabular}{llccc}
\hline No. & Patient & Gender & Age (years) & Diagnosis \\
\hline 1. & R.C. & M & 26 & LAM4 \\
2. & L.I. & F & 30 & LAM4 \\
3. & S.T. & M & 20 & LAM4 \\
4. & V.R. & M & 26 & LAM5 \\
5. & P.S. & F & 50 & LAM4 \\
6. & M.S. & M & 42 & LAM5 \\
7. & F.B. & M & 33 & LAM4 \\
8. & S.E. & M & 50 & LAM4 \\
9. & P.B.C. & M & 29 & LAM4 \\
10. & C.N. & M & 55 & LAM2 \\
11. & V.L. & F & 43 & LAM4 \\
12. & C.R. & M & 32 & LAM4 \\
13. & K.G. & F & 33 & LAM5 \\
14. & Z.I.E. & F & 33 & LAM4 \\
\hline
\end{tabular}

M - male, F - female, FAB classification: LAM4, LAM5, LAM2

$<5 \%$ blasts, resolution of previously abnormal cytogenetics, no evidence of extramedullar leukemia, absolute neutrophil count $(\mathrm{ANC})>1500 / \mu \mathrm{L}$, and platelets > $140,000 / \mu \mathrm{L}$. When patients achieved complete remission after induction treatment, we performed mobilization regimens using chemotherapy (Cyclophosphamide 2-4 $\mathrm{g} / \mathrm{m}^{2}$ ) and granulocytic colony stimulating factor (Neupogen $10 \mu \mathrm{g} / \mathrm{kg}$ ) followed by peripheral stem cell collection. In 4 patients we had double mobilization of stem cells, the second mobilization was performed only with growth factor, necessary to drive a sufficient number of hematopoietic stem cells.

In the autologous peripheral stem cell transplantation the following conditioning regimen was administered: $\mathrm{Bu}$ (Busulfan $16 \mathrm{mg} / \mathrm{kg}$ ) to 4 patients; BuCy (Busulfan $16 \mathrm{mg} /$ $\mathrm{kg}$, Cyclophosphamide $120 \mathrm{mg} / \mathrm{kg}$ ) to 9 patients and the last patient received BuMel (Busulfan $16 \mathrm{mg} / \mathrm{kg}$, Melphalan $140 \mathrm{mg} / \mathrm{m}^{2}$ ).

All patients received the harvested stem cell product by infusion. In the post-transplant period for all patients were given G-CSF (Neupogen) to accelerate the engraftment.

Table III. Number of days to engraftment after PBSC transplantation

\begin{tabular}{llll}
\hline No. & Patient & $\begin{array}{c}\text { Neutrophil engraftment } \\
\text { time }\end{array}$ & $\begin{array}{c}\text { Platelet engraftment } \\
\text { time }\end{array}$ \\
\hline 1. & R.C. & +11 days & +12 days \\
2. & L.I. & +12 days & +14 days \\
3. & S.T. & +10 days & +11 days \\
4. & V.R. & +14 days & +16 days \\
5. & P.S. & +14 days & +17 days \\
6. & M.S. & +15 days & +16 days \\
7. & F.B. & +12 days & +14 days \\
8. & S.E. & +9 days & +10 days \\
9. & P.B.C. & +13 days & +19 days \\
10. & C.N. & +12 days & +15 days \\
11. & V.L. & +12 days & +14 days \\
12. & C.R. & +10 days & +13 days \\
13. & K.G. & +11 days & +14 days \\
14. & Z.I.E. & +9 days & +12 days \\
\hline
\end{tabular}

Table II. Number of collected stem cells

\begin{tabular}{llc}
\hline No. & Patient & Total No. of CD34+ cells $\times 106 / \mathrm{kg}$ b.w. \\
\hline 1. & R.C. & 4.67 \\
2. & L.I. & 1.64 \\
3. & S.T. & 4.81 \\
4. & V.R. $^{*}$ & 1.31 \\
5. & P.S. $^{*}$ & 1.14 \\
6. & M.S. & 1.82 \\
7. & F.B. & 1.57 \\
8. & S.E. & 5.77 \\
9. & P.B.C. & 1.52 \\
10. & C.N. & 1.57 \\
11. & V.L. & 1.06 \\
12. & C.R. & 3.42 \\
13. & K.G. & 2.34 \\
14. & Z.I.E. & 6.00 \\
\hline
\end{tabular}

B.w. - body weight, ${ }^{\star}$ Double mobilization

Patients were isolated in conventional laminar airflow rooms during the period of aplasia. Prophylactic oral antibiotics, antimicotic and antiviral treatment were started to prevent infections. If an infection was suspected, blood samples were taken and wide spectrum antibiotics were initiated. The antibiotic treatment was readjusted after microbiological culture results. Each case necessited supportive care with platelet and erythrocyte transfusion, these products were irradiated with $25 \mathrm{~Gy}$.

\section{Results}

Peripheral blood stem cells contained a median number of $2.76 \times 10^{6} / \mathrm{kg} \mathrm{CD} 34+$ cells b.w. (range 1.06-6.00). In 9 patients the collected number of stem cells was $<2.5 \times$ $10^{6} / \mathrm{kg} \mathrm{CD} 34+$, in 5 patients $>2.5 \times 10^{6} / \mathrm{kg}$ CD34+ cells.

All the patients were transplanted successfully, all of them achieved a sustained neutrophil count $(>0.5 \mathrm{G} / \mathrm{L})$, median time 11 days $(9-15)$ and platelet count $(>20 \mathrm{G} / \mathrm{L})$ median time 14 days (10-19) after transplantation.

Between patients with CD34+cell dose $<2.5 \times 10^{6} / \mathrm{kg}$ $(\mathrm{n}=9)$ or $>2.5 \times 10^{6} / \mathrm{kg}(\mathrm{n}=5)$ we observed significant differences regarding neutrophil engraftment: 11 days

Table IV. Results of PBSCT

\begin{tabular}{llc}
\hline No. & Patient & Evolution after transplantation \\
\hline 1. & R.C. & $>9$ years OS and DFS \\
2. & L.I. & Died ( relapse) \\
3. & S.T. & $>7$ years OS and DFS \\
4. & V.R. & $>6$ years OS and DFS \\
5. & P.S. & $>6$ years OS and DFS \\
6. & M.S. & $>5$ years OS and DFS \\
7. & F.B. & $>5$ years OS and DFS \\
8. & S.E. & Died (relapse) \\
9. & P.B.C. & Died (relapse) \\
10. & C.N. & Died (cardiac toxicity) \\
11. & V.L. & Relapse \\
12. & C.R. & Remission \\
13. & K.G. & Died (viral infection) \\
14. & Z.I.E. & Relapse \\
\hline
\end{tabular}

OS - overall survival, DFS - disease free survival 
(range 9-11) and 13 days (range 11-15), and the same difference was present regarding platelet engraftment: 12 days (range 10-13) and 15 days (range 14-19).

This short duration of neutropenia contributed to the low morbidity. Infective complications occurred in $45 \%$ of the patients. Transfusion requirements were low, patients requiring a median of 3 units of red blood cells and 5 platelet transfusions.

The main extra-hematological toxicities were mucositis (grade 1-2), diarrhea, nausea, cardiac arrhythmia, hypertension, hepatic and cardiac toxicity.

From the 14 patients who received autologous stem cell transplantation there were 2 deaths within 100 days of the transplant: 1 with cardiac toxicity at day +12 and 1 with severe viral infection and acute inflammatory demyelinating polyradiculoneuropathy.

Six of the patients remained more than five years in complete remission after autologous stem cell transplantation. One of the patients achieved complete remission and returned to his everyday work and activities.

Leukemia progression was observed in 5 patients, 3 of them died within 1 year of transplantation. Two cases had relapsed after PBSC transplantation, one of them after 10 months, the second after three months. At the moment, they receive chemotherapy and allogeneic transplantation from unrelated donors will be performed.

\section{Discussion}

In our study we analyzed the role of autologous SCT in patients with AML with low and intermediate risk who do not have an identical sibling donor.

Numerous studies have demonstrated that rapid engraftment depends on the number of CD34+ cells $[8,9]$. We observed that infusion of CD34+ cells $>2.5 \times 10^{6} / \mathrm{kg}$ is associated with faster neutrophil and platelet engraftment.

The conditioning regimen seemed to be well tolerated, without impairment of organ function or relevant extrahematological adverse event.

Irrespective of the choice of ASCT or chemotherapy, relapse of leukemia remains the predominant cause of treatment failure $[10,11]$. Earlier studies reported the results of auto-SCT for AML patients in CR1 with favorable cytogenetics were better than those observed with conventional chemotherapy $[12,13]$. In our study the higher relapse was associated in patients with intermediate-risk cytogenetics. In this group of patients allo-SCT emerged as the treatment of choice [14].

In multivariate analysis, the age of patients at transplant emerged as an important prognostic factor for overall survival and disease-free survival. Older patients more often have poor-risk leukemic characteristics, chemoresistant profile and severe comorbidities than younger patients, and tolerate prolonged aplastic periods and intensive therapy less well
$[15,16]$. We were not able to evaluate this factor since a significant number of patients were not transplanted.

\section{Conclusions}

We conclude that autologous stem cell transplantation is an effective treatment for patients with acute myeloid leukemia without human leukocyte antigen-matched (HLA) sibling donor. Auto-SCT generated a long-term disease free survival, particularly in patients with standard risk disease.

\section{References}

1. Apperley J, Carreras E, Gluckman E, Masszi T. The EBMT Handbook Haematopoietic Stem Cell Transplantation. $6^{\text {th }}$ Revised Edition. 2012:317326

2. Tsimberidou AM, Stavroyianni N, Viniou N. Comparison of allogeneic stem cell transplantation, high-dose cytarabine, and autologous peripheral stem cell transplantation as postremission treatment in patients with de novo acute myelogenous leukemia. Cancer. 2003;97(7):1721-1731.

3. Büchner T, Berdel WE, Schoch C, et al. Double induction containing either two courses or one course of high-dose cytarabine plus mitoxantrone and postremission therapy by either autologous stem-cell transplantation or by prolonged maintenance for acute myeloid leukemia. J Clin Oncol. 2006; 24(16):2480-2489.

4. Harousseau JL, Cahn JY, Pignon B, et al. Comparison of autologous bone marrow transplantation and intensive chemotherapy as postremission therapy in adult acute myeloid leukemia. Blood. 1997;90(8):2978-2986.

5. Isidori A, Bonifazi F, Visani G, et al. Autologous stem cell transplantation for acute myeloid patients in first complete remission: a 10-year follow-up study of 118 patients. Haematologica. 2005;90:139-140.

6. Suciu S, Mandelli F, de Witte T, et al. EORTC and GINEMA Leukemia Groups- Allogeneic compared with autologous stem cell transplantation in the treatment of patients younger than 46 years with acute myeloid leukemia(AML) in first comlete remission(CR1): an intention-to-treat analysis of EORTC/GIMEMA AML-10 trial. Blood. 2003;102:1232-1240.

7. Wang J, Ouyang J, Zhou R, et al. Autologous hematopoietic stem cell transplantation for acute myeloid leukemia in first complete remission: a meta-analysis of randomized trials. Acta Haematol. 2010;124(2):61-71.

8. Gordon MY, Blackett NM, Lewis JL, et al. Evidence for a mechanism that can provide both short-term and longterm haemopoetic repopulation by a seemingly uniform population of primitive human haemopoetic precursor cells. Leukemia. 1995;9:1252-6.

9. Villaon L, Odriozola J, Larana JG, et al. Autologous peripheral blood progenitor cell transplantation with <2x 10(6) CD34(+)/kg: an analysis of variables concerning mobilisation and engraftment. Hematol J. 2000;1: 374-81.

10. Vellenga E, van Putten W, Ossenkoppele GJ, et al. Autologous peripheral blood stem cell transplantation for acute myeloid leukemia. Blood. 2011;118(23):6037-42.

11. Ferrara F. Renaissance of autologous stem cell transplantation for AML? The Lancet Oncology. 2012;13(2):121-3.

12. Mehta J, Powles R, Sirhohi B, et al. Impact of cytogenetics on the outcome of autotransplantation for acute myeloid leukemia in first remission: is the benefit of intensive pre-transplant therapy limited to patients with good karyotypes. Blood. 2001;98(Suppl 1):716a.

13. Linker C. The role of autologous transplantation for acute myeloid leukemia in first and second remission. Best Pract Res Clin Haematol. 2007;20:77-84. Review.

14. Gorin NC, Labopin M, Frassoni F, et al. Identical outcome after autologous or allogeneic genoidentical hematopoietic stem-cell transplantation in first remission of acute myelocytic leukemia carrying inversion 16 or $\mathrm{t}(8 ; 21)$ : a retrospective study from the European Cooperative Group for Blood and Marrow Transplantation. J Clin Oncol. 2008;26:3183-3188.

15. Thomas X, Suciu S, Rio B, et al. Autologous stem cell transplantation after complete remission and first consolidation in acute myeloid leukemia patients aged 61-70 years: results of the prospective EORTC-GIMEMA AML-13 study. Haematologica. 2007;92:389-396.

16. Burnett AK, Mohite U. Treatment of older patients with acute myeloid leukemia-new agents. Semin Hemat. 2006;43:96-106. 